\title{
The 2D Classification of Learning Motivation and The Analysis on Its Mechanism of Action
}

\author{
ZhangLingling ZhangTing MaHongbo \\ The Engineering and Technical College of Chengdu University of Technology, Leshan, \\ Sichuan, 614000
}

\begin{abstract}
Learning motivation is one of the key components of individual learning motivation system. Learning motivation can be divided into Intrinsic Motivation and Extrinsic Motivation according to its sources. It also can be divided into Direct Motivation and Indirect Motivation according to whether it can motivate the learning behavior directly. Thus the twodimension classification system is formed, which talks about the drive effects of various motivations on the learning behavior and the way in which it happens as well as its mechanism.
\end{abstract}

Keywords: learning motivation, twodimension classification, mechanism analysis

Among all the components of learning motivation system, learning motivation is one of the important components, which has primary effect on learning behavior. The research about learning motivation is always an important topic and there exists a lot of related studies. Scholars put forward their own wonderful opinions from different aspects such as Psychology and Behavioural Science. By doing an investigate and research about the learning motivation among about 1,000 college students, and learning from other scholars' studies, the author analyses and gives a conclusion about two-dimension classification of the learners' learning motivation and its mechanism of action to the learning behavior.

\section{Two-dimension Classification of the Learning Motivation}

Learning motivation is a kind of internal launch mechanism which means to motivate the individual to start learning activities and to maintain the existent ones with a certain goal. The key point of the author's research is to discuss the drive effect of different motivations on the learning behavior. And the purpose of classifications is to do a further research of the effect and mechanism of various motivations. So the author will classify the motivation mainly from two aspects as below.

\subsection{Intrinsic Motivation and Extrinsic Motivation}

Motivation can be divided into Intrinsic Motivation and Extrinsic Motivation on the basis of its source and the classification standard is different from Educational Psychology. According to the theory of Educational Psychology, " On the basis of its source, learning motivation can be divided into Internal Learning Motivation and External Learning Motivation. Intrinsic Motivation also can be called Intrinsic Motivation Effect which means the motivation 
caused by the individual's internal need. For example, the intrinsic motivation factors, such as students' thirst of knowledge, interest, aspiration to improve their own ability, will prompt them to study actively. Extrinsic Motivation also can be called Extrinsic Motivation Effect which means the motivation caused by the external inducements." ${ }^{[1]}$ It can be known as that even the Extrinsic Motivation is the motivation of the individual's psychology and it is just caused by external inducements. So we can infer that Intrinsic Motivation is independent of Extrinsic Motivation. But in fact, can the intrinsic motivation factors such as thirst of knowledge, interest, aspiration to improve their own ability come into being without external factors? In like manner, can the external inducements become motivations without the effect of internal need? This kind of argument doesn't really stand up to scrutiny. So the paper won't adopt it.

The paper considers that the source of motivation can be divided into internal and external ones. The basis of the extrinsic motivation's existence is that learning motivation doesn't just come from the individual's conscious mind. In fact, learning and teaching are always coexisting as two aspects of a thing. Therefore, the learning motivation can not be analyzed only from the individuals. Actually, there is one important kind of motivation coming outside the individual, which comes from their parents, teachers, schools and the society. All of them influences the individual's learning profoundly by carrying out education effectively. As the external learning environment, they impose their own motivation on the individual on purpose or unwittingly. This kind of motivation cannot be ignored. In fact, education activity is always endued the function of "humanization". One of the important goals of education is cultural heritage. Educators filtrate, organize and design the teaching contents and forms obedience to a certain social and cultural values. They make the society's and their own education motivation run through the process of the teaching and learning, which has strongly influenced the learners' learning behavior. If we only study the learning motivation from the individual's psychology and totally ignore the external environment, our understanding of the motivation will be surely narrow and limited and we couldn't get a comprehensive understanding about the composition of motivation. Therefore, the extrinsic motivation in this paper implies a kind of environmental impact which is outside the individual and can influence their learning behavior. Those, which are the motivations from the individual's psychology and the trigger mechanism of maintaining learning behavior, are called Intrinsic Motivation.

\subsection{Direct Motivation and Indirect Motivation}

Motivation can be divided into Direct Motivation and Indirect Motivation according to whether it can motivate the specific learning behavior directly or not. Not every motivation can motivate specific behaviors, some motivations imply an abstract goal. For example, honor motivation motivates the individual to pursue the recognition and avoid to get negative estimate. This is an abstract goal and its premise is usually that to get a complimentary achievement(result). Only when this kind of motivation is practicable in some specific areas, like getting excellent results in learning or outstanding achievement in work, it can motivate the learning behavior. This kind of motivation is called indirect motivation. Those, which aim at the specific areas 
and can motivate the individual's learning behavior directly, are called direct motivation. For example, learners' interest and hobby about something can motivate them to approach the goal object itself and to explore the inherent law actively. Thus it will cause the learning behavior about something.

Therefore, the two kinds of classifications are considered as two dimensions of the 2D analytical method and various learning motivations can be divided into four types: Extrinsic Direct Motivation, Extrinsic Indirect Motivation, Intrinsic Direct Motivation, and Intrinsic Indirect Motivation. Every specific motivation belongs to one of the types as shown in the Table1.

Table1:The 2D Classification of Learning Motivation

\begin{tabular}{|c|c|c|}
\hline & Direct & Indirect \\
\hline $\begin{array}{l}E \\
x \\
t \\
r \\
\text { i } \\
n \\
s \\
\text { i } \\
c\end{array}$ & $\begin{array}{l}\text { 1. direct } \\
\text { intervening from } \\
\text { parents } \\
\text { 2. order of teachers } \\
\text { 3.school teaching } \\
\text { management } \\
\text { 4. related } \\
\text { stipulation from } \\
\text { government's } \\
\text { education } \\
\text { management } \\
\text { department } \\
\text {...... }\end{array}$ & $\begin{array}{l}\text { 1. social } \\
\text { identification } \\
\text { 2. parents } \\
\text { expectation } \\
\text { 3. results of the } \\
\text { examination } \\
\text { 4. ranking in the } \\
\text { school(class) } \\
\text { 5. employment } \\
\text { pressure } \\
6 \text {. salary and } \\
\text { occupation } \\
\text { development }\end{array}$ \\
\hline $\begin{array}{l}\mathrm{I} \\
\mathrm{n} \\
\mathrm{t} \\
\mathrm{r} \\
\mathrm{i} \\
\mathrm{n} \\
\mathrm{s} \\
\mathrm{i}\end{array}$ & $\begin{array}{l}\text { 1. instinct } \\
\text { 2. curiousness } \\
\text { 3. interest } \\
\text { 4. hobby } \\
\text { 5. understanding of } \\
\text { learning } \\
\text { 6. habit } \\
\text { 7. sense of } \\
\text { competition }\end{array}$ & $\begin{array}{l}\text { 2. achievement } \\
\text { expectations } \\
\text { 3. anticipation of } \\
\text { development } \\
\text { 4.mission(respons } \\
\text { ibility)awareness } \\
\text { 5. sense of honor } \\
\text { 6. fair of failure }\end{array}$ \\
\hline
\end{tabular}

\section{Analysis of various motivations' action mechanism}

All the four types of motivations mentioned above can motivate the learners' learning behavior. But the ways in which the effect works and its mechanism are different. Details are as follows.

\subsection{Extrinsic Direct Motivation}

This kind of motivation is from outside the learners. It is a kind of environmental impetus which can cause and maintain the learners' learning behavior directly. This kind of motivation comes from the environmental objects including parents, schools and teachers' prospection of the learning subjects for several aspects, such as their learning target, learning contents, learning environment, learning process as well as learning strategy. It makes some requirements for the subjects' learning behavior from all or one of the aspects usually with mandatory characteristics of different degrees. Extrinsic Direct Motivation can cause some behavioral effects on the learners conveniently and efficiently to a certain extent. It can meet the external behavior requirement with least communication costs and time. Generally speaking, Extrinsic Motivation is a kind of short-term motivation or periodic motivation and it can only influence the observed external behavior of learners. When the internal learning motivation of the subject hasn't been mature or cannot motivate the learning behavior yet with its original driving force, proper extrinsic direct motivation can motivate the learning behavior with its understanding of the learning. It also can play a helpful role in learners' developing good learning habits. For example, teachers usually make some rules for the students like that students must go to school on time, listen to the teachers carefully, obey classroom discipline, keep right sitting posture and can't do things that doesn't have anything to do with the class and so on. These rules and measures will do good for students to develop good learning habits and learn to concentrate on the study. 
While these rules are from outside the learners, they can only play a part in the observed external behavior of the learners', but can't completely eradicate them to sneak off in their mind.

\subsection{Extrinsic Indirect Motivation}

This kind of motivation is from outside the subjects. It doesn't stipulate the learners learning behavior directly. It can motivate the subjects' learning behavior indirectly by inducing internal motivation of the subjects. It is the environmental triggering factors of Intrinsic Motivation. They usually come from some external subjective expectations or objective realities. When these external factors are not realized or resonated by the subjects, they can't influence the subjects. When these factors are accepted by the subjects, they may also not motivate the learning if the learners can accomplish it without any efforts. Only when these external factors are totally accepted and resonated by the subjects who realize that they cannot achieve the expectation or eliminate the threat at present and when they believe it is possible or they are capable to achieve it only through a certain learning behavior, Extrinsic Motivation can have effects on the subjects' learning behavior. This process is called Internalization of Extrinsic Motivation. For example, only when the social identity and parents' expectation are accepted by the subjects and translated into their own life faith, achievement expectations, or the development expectations, and that the subjects realize they can achieve the expectations only through their efforts, the social identity and parents' expectation can motivate the learning behavior.

\subsection{Intrinsic Direct Motivation}

This kind of learners' motivation comes into being spontaneously and it is the inducement which can motivate learning behavior. These inducements can be endogenic. For example, the demand of food for living will force human beings to learn how to get food. The curiosity of something will make people approach it and try to learn about it. These inducements also can be ectogenic. For example, the motivation of competition sense to the learning behavior may be caused by the combined actions of some indirect motivations, such as achievement expectations, sense of honor, fear of failure, and the subjects' judgment of the situation. However, those intrinsic indirect motivations like achievement expectations, sense of honor, fear of failure just come from some extrinsic indirect motivations such as social identity and parents' expectation. Some intrinsic direct motivations have both endogenic and ectogenic characteristics. For example, interests can be aroused by the achievement and the development expectations. They may also be aroused by curiosities without any utilitarian expectations. $^{[2]}$ Some intrinsic direct motivations are transformed from ectogenic inducements into endogenic inducements through ectogenic inducements' solidification. For example, the external requests of learning behavior are typical ectogenic inducements which can become a kind of learning habit through a long-term training. When the habit is finally formed, it will become endogenic direct inducement. It may not represent any definite and specific goals but just a kind of self-compulsive psychological feature.

\subsection{Intrinsic Indirect Motivation}

This kind of motivation is tendencious motivation coming from learning 
subjects' consciousness. It usually directs to some long-dated goals or results. The consciousness of the long-dated goals or results will motivate the subjects to adopt some proper ways to achieve or avoid them. The tendencious motivation means that it can motivate the subjects to do something but it only can motivate the goal-directed behavioral intention and is not effective on the specific learning behavior. That means Intrinsic Indirect Motivation can not definitely cause learning behavior. Only when they are transformed into Intrinsic Direct Motivation, they can motivate the learning behavior. For example, if the fear of failures can not be transformed into strong sense of competition and the learners can not adopt some specific learning methods, it may be finally transformed into the fear or evasion of learning itself.

\section{The Source of Intrinsic Motivation}

From The 2D classification of learning motivation and the analysis on its mechanism of action, we can find that it is the Intrinsic Motivation that can really motivate the subjects' learning behavior constantly and effectively. External motivations can only have some periodical and explicit effects on the learning behavior and they can only motivate the learning behavior by influencing the internal motivation. Therefore, it is necessary for us to deeply analyze that how the Intrinsic Motivation can motivate the learning behavior effectively.

The author considers that the source of those initiative and continuable power which can promote the human behavior can be retrospected as two original characteristics of humanity which are desire and fear. The most classical Maslow's Hierarchy of Needs Model actually describes different levels of human's desires which are from the most basic desire of living to the higher level desire of social identity and selfactualization. And every desire usually coexists with the fear. For example, the desire of living usually coexists with the fear of death. The desire of social identity usually coexists with the fear of being abandoned by the society. Without any desire, driving force of motivating the behaviors will no longer exist. In the area of education and learning, the psychologies that are formed by desire and fear are called Expanding Psychology and Protective Psychology of human beings.

Expanding Psychology motivates the individual to get or achieve something to show that life is existing and healthy and vigorous. The target objects of expanding may be material or immaterial through different values. When the individuals realize that they can achieve a certain expanding goals by learning and exploring, they will feel a kind of excitement involuntarily in their mind. This kind of excitement is the expectation of pleasant sensation which can be felt when the individual has finally realized self-development or self-transcendence. It also can intensively stimulate the individual's learning behavior. The interests caused by pure curiousness is of course the form of expression of expanding motivation, but the expectation of future achievement and development basing on the individual's present situation is really the typical form of expanding motivation. The learning behavior motivated by Expanding Psychology is usually optimistic and aggressive.

Protective Psychology usually makes people tend to do something to avoid getting some undesired results. When the individuals realize that if they cannot get a good learning performance, they will certainly get some miserable results, the 
feeling of anxiety even fear in their hearts will arise spontaneously. In most situations, the anxiety and fear can motivate the subjects' learning behavior. For example, when the subjects realize that if they don't study hard, they will be discriminated as weak students, lose parents' love or can't find a good job and so on, the motivation of anxiety and fear will work. It stands to a reason that everyone should have this kind of selfpreservation psychology, but we can always find that sometimes its motivation to the subjects doesn't work. The main reason is that the subjects usually have different value identities of the results and different expectations of the hard working. For example, some students are quite used to be weak students and even have negative and hostile feelings to it. And some students just believe there are some social factors of the reasons why they are considered as weak students, lose their parents's love and can't find a good job but they don't think of the expectations $^{[3]}$ that their learning behavior could reach. In these situations, the regular nervous and afeared psychology mentioned above has been changed into slack and apathic ones or equilibrated and protected by other psychology mechanism. Then they can no longer motivate the learning.

Both of two kinds of psychology mentioned above can motivate learning behavior effectively, but because of the different mechanisms of action, the individuals' learning experiences are totally different. The learning behavior motivated by Expanding Psychology usually makes learners feel that they can find pleasures in studying, however, the learning behavior motivated by Protective Psychology usually represents "hardworking". In fact, the two kinds of psychology usually affect the learning alternately or together. For example, we often see that students from poor families have stronger learning desire than the students from rich families do. The reason is that they experience poverty and they know well about the dilemma caused by family economic status. They will study very hard in order not to continue the elder generation's poverty and to change their own and the family's destiny. Among their learning motivations, there are some protective psychology of breaking out of the poverty. There also exists some expanding happiness such as good vision of future, sense of achievement in learning and interest of something in some areas.

In conclusion, Intrinsic Motivation originating from the basic primitive characteristic of human beings can affect the learners directly and permanently and can really cause a good learning performance. The degree depends on some factors' interaction including the learners' personality development, values and abilities. For the educators, that how to make use of proper external effects to influence the learners'intrinsic motivation and make them motivate the learning behavior effectively needs some purposeful researches according to the learners' practical situations. This is what the artistry of education reflects.

\section{References}

[1] FengZhongliang, WuXinchun etc. "Educational Psychology" (2nd. Edition). Beijing, People's Education Press, 2010.

[2] Zhangkai, "Interest and Learning" , A Renascent Research Field, Journal of Ningbo University(Education Science Edition), 2002(2).

ZhaoJing, Zhailei, "Learning Motivation and Teaching Improvement ", Proceedings of 2010 Third International Conference on Education Technology and Training(Volume 7). 